\title{
System Structure and System Architecture of Digital Campus
}

\author{
Jie Zhou \\ Network Information Center, Dalian JiaoTong University, Dalian, China \\ zj@djtu.edu.cn
}

Keywords: Digital campus; System; System architecture

\begin{abstract}
With the continuous development of information technology and its wide application in the field of education, the implementation of higher education informatization is imperative. Digital campus is regarded as the highlight of educational information, especially attention. This article starts with the overall planning of digital campus, and through analysis of the main content and system structure of digital campus construction, and then studies the macro program of the implementation of digital campus construction.
\end{abstract}

\section{Introduction}

The construction of digital campus is one of the three major themes of education informationization. It has been listed in the development plan of the major institutions, and it is to promote the education informationization work has entered a new historical stage. It is not only an important foundation for the modernization of education, but also an important means of the universities to improve their management level and comprehensive competitive strength. The level of the construction of digital campus has become an important embodiment of the level of running a school, the image and status of the university.[1]

\section{The Overall Plan for the Construction of Digital Campus}

The construction of digital campus is based on the first advanced information technology, and the infrastructure of campus network is as the basis of exchange platform. On the basis of the network hardware and software platform, according to the operation management system , in accordance with the standards and requirements, application center, resource center and security center which is people-oriented will be established. In order to form a digital scientific research environment, teaching environment, environment and living environment.

\section{The Main Content and System Structure of Digital Campus Construction}

The concept of digital campus is not only the construction of information technology level, cultural level, but also relates to the school every construction aspect. It covers many aspects of the campus life and its construction contents include several aspects. According to the application level of the system can be divided into three aspects: infrastructure, platform and application system.

Infrastructure Construction. Infrastructure of campus network. Campus network is the main carrier of digital campus, including two categories: wired network and wireless network. To make the campus network structure clear and reasonable data network requires the use of distributed routing. Combined with the campus wireless network and wired network, to achieve complete coverage in the school. Student dormitory, auditorium, conference rooms and other areas can achieve high density, high bandwidth wireless access. Unified authentication and billing management of wireless and wired network can be achieved. That can provide a variety of network security mechanism. Construction of teaching room and electronic reading room. Teaching room and electronic reading room is mainly used for computer teaching and searching for information on the Internet. Number of computers should be equipped with the ratio of students and teachers. At the same time, it has the function such as fire prevention, anti-theft, waterproof and lightning protection etc. Each computer room is equipped with an independent server as a teacher's 
machine and an electronic teaching platform is installed. Construction of network multimedia classroom and voice laboratory. The multimedia classroom is connected with multimedia control center through network. That can be easy to control all the multimedia teaching system. It can realize the centralized management sharing, remote live and on-demand network, upload and download of multimedia teaching resources. Construction of campus security system. Campus security system including monitoring system, alarm system, patrol system. Through the camera, sensors and other electronic equipment, it can transmit the dynamic situation of the office, research, storage and parking to the central monitoring room. That can improve the sensitivity and accuracy of anti-theft, fire prevention and accident prevention. Construction of campus broadcast network. Network audio broadcasting system for the campus application, provide teaching and management application interface based on campus environment, realize rich campus applications, such as automatic music bell, remote broadcast, personalized broadcast, network broadcasting, audio on demand, leading online speech, voice real-time gathering and broadcasting, background music, sound amplification, remote control, batch control, regular radio management, permissions and other functions.[1]

Construction of Sharing Platform. Construction of information standards. Digital campus must follow improve and perfect the standard content based on the national and the Ministry of education standard, formulate the information encoding standard of school, unified data exchange standard, form a complete set, in accordance with the school situation and the informatization standard system for future development, to avoid confusion of the information standard and avoid information not be exchanged and shared. Construction of sharing data. In order to realize data sharing in digital campus, we must formulate a unified data dictionary, a global database, construct data integration platform, realize the data sharing, formulate unified database construction standard of service system, build a data analysis model in order to support the continuous operation for system. unified identity authentication platform. In order to solve the problem of the username and password are not unified for different application systems, digital campus provides password authentication method and unified authorization mechanism and a set of programme. Users use a name and password can login all application system which they have rights. It supports centralized user authentication and authorization mechanism, realize single login. Users can access other authorized applications without login authentication after login any application. Unified campus portal platform. Unified campus portal platform is located above all kinds of applications. It is the window to show the application of digital campus. It can display the application information of digital campus by browser. It can effectively integrate gaps between different applications. It can provide secure access and personalized application interfaces tailored for specific users to access critical business information according to the characteristics, preferences and roles of each user. Teachers and students can browse to related data and deal with related transactions.[2]

Application System Construction. Office Automation. It is used for the daily management of the business office, paperless office. It mainly includes online office, document circulation, announcement, conference management, archives management, school affairs disclosure, the petition work as well as some commonly used query module. Campus card system. The purpose of campus card system is to realize "one card in hand" and "go all over campus", one card is universal, one card is multi-purpose". Campus cards can be used as library cards, computer cards, meal cards, medical cards, bath cards, shopping cards, access cards, parking cards, bus cards and so on. Enrollment system. It can be used to obtain enrollment data, and to publish data to the data sharing platform for other management systems (library management, campus card management, orientation system, etc.) use. Orientation system. According to the original enrollment data, Freshmen apply for admission. Freshmen receive the campus card and credit card reporting. The procedure is simplified. The orientation system is also connected with the student status system and the student apartment system to provide new data. Student management system. The existing student management system and educational administration school system can be docked. The daily management of students is based on student data, including scholarship management, student loans management, funding management, disposition management, etc. Employment system. According 
to the graduates data, carry out graduate employment guidance and service, mainly including job recruitment, employment education, employment management, employment sites. School departure system. Docked with student management system and based on graduate data to handle school departure procedure. Alumni system. Docked with employment system and school departure system, based on the school departure system data to develop alumni association work, including alumni information management, alumni records, alumni forums and alumni websites. Educational administration system. It can be used for teaching plan, arrangement of courses, classroom management, course selection, achievement management, evaluation of teaching, discipline construction and management of training bases. Network teaching system.[3] It can be used for online lesson preparation, courseware support, quality course construction, material construction, network instruction, online self-study and communication, network examination and so on, so as to meet the application needs of network distance education and lifelong education. Financial management system. It can be used for the management of the school's financial information, including fees, expenses, cost budget, assets purchase, storage, use and so on. Personnel management system. It can be used for managing school personnel information, including the number of person, personnel file maintenance, title Evaluation Management, annual assessment management and so on. Scientific research and foreign affairs management system. It can be used for scientific research and foreign affairs project management, including project declaration, process management, fund management, evaluation, inquiry of the completion project, scientific research status of people abroad, application and management of foreign affairs personnel entering school. Library management system. It can be used for library information management, including bibliographic inquiry, book borrowing, book cataloging, book storage, electronic books, video books, book procurement and so on. Logistics management system. It can be used for the management of school logistics, including routine management, industrial management, cost accounting, integrated management to assist the logistics manager to manage the work better. Asset management system. It is used for the management of school fixed assets, including the purchase, management and discarding of the fixed assets of the school. It can provide timely, effective and reliable data for asset management and equipment management. Leadership decision support system. It is used for the decision management based on each system at the front including data mining, information inquiry, data comprehensive analysis, auxiliary decision-making and so on.

\section{The Planning Process of Digital Campus}

Digital campus planning should be considered not only from longitudinal time and development, but also transverse coordination of relationship from all the departments and other agencies on the outside. It is necessary to consider the construction of digital campus project step by step of the infrastructure construction, informatization construction, public information resources application platform construction, application system construction, the supporting system construction such as, but also consider the coordinated development of these projects. The plan of digital campus in university is divided into three steps: pre-phase analyses, scheme design and evaluation and improvement.[4]

Pre-phase Analyses. The pre-phase analyses is an important stage of development of the digital campus of the overall planning. Through the system analysis, we can understand the status of digital campus construction at the present stage, determine the overall demand for the construction of digital campus, planning concept of building digital campus. In this stage, it is necessary to conduct a comprehensive survey of the existing digital campus construction, and analyze the achievements and problems existing in the digital campus. Go deep into all departments to understand the requirements of each user group for digital campus. Through the scientific and rational analysis of digital campus construction, we can effectively improve the quality of education and teaching, improve the innovative ability and raise the level and specifications of personnel training.[5]

Scheme Design. At planning and design stage, it is mainly through the pre needs collection to clear overall structure and technical ideas, mainly through the establishment of digital campus planning objectives to plan specific construction tasks. Finally, combine specific construction to 
arrange implementation. The goal of digital campus in universities must be formulated on the basis of analyzing the current situation, defining the needs and defining the concept. According to demand, the goal of digital campus can be divided into long-term goal and short-term goal. The long-term goal is mainly from the final implementation function of the digital campus. The short-term goal pays more attention to short time effect and stage implementation. Through the evaluation of short-term goals, the implementation of the digital campus can be better protected. In this stage, identify goals through requirements analysis. Focus on the important projects and tasks which will be needed to achieve the goals. Actually, it will come from hardware, software, resources, application, training, management and protection. Digital learning environment is the use of multimedia, network technology. Digitalize the school's main information resources, and build a suitable way of management, and thus forming an information environment for training talents. The construction of campus basic network is the foundation of the construction of digital learning environment. At the same time, with the development of network technology and the increase of the demand for campus network services by both teachers and students, the network construction needs to be constantly upgraded. Digital learning resources construction is an important task of digital campus construction. The construction of digital resources should be based on technology platform and guided by the change of educational teaching idea. In the integration of all kinds of teaching resources, we should pay attention to three aspects: digital library, characteristic resource library construction and teacher training. The teacher is an important practice carrier during the process of carrying digital learning. Teachers' comprehensive quality and abilities of using digital learning resources for teaching, ability of scientific research and teachers' understanding of digital learning, will produce important influence on the practice of University Digital learning. This requires systematic training to form a teacher's awareness and ability to develop digital learning. Planning implementation is an important part of planning. That needs to be secured from budget, organization, and time. Through the clear function of each department, to ensure that funds and personnel, form organization to carry out the plan. In practice, the leadership of the school principal is directly responsible for the digital learning environment construction and specialized institutions will be responsible for planning, organizing and coordinating the relevant work. Scientific and reasonable budget is the guarantee of building digital campus in Colleges and universities. In the budget for the digital campus, a long-term budget needs to be made based on the development of the digital campus. The budget includes not only hardware infrastructure and other tangible assets, but also includes the software resources construction, teachers training, management, maintenance and upgrade and material incentive to encourage the reform of education informationization. The construction of digital campus is not easy, it needs a long-term process of construction, and a gradual development strategy implementation. It often due to unforeseen factors makes the digital campus is longer than the scheduled time. Therefore, in the implementation process of digital campus construction, it is necessary to control the time schedule of digital campus construction through phased arrangement. Learn from the successful experience of foreign universities, introduce CIO (Chief Information Officer) system into decision making layer of University. CIO and department of information technology formulate the overall planning of information construction. That is the inevitable choice for the application of information technology in education.[6]

\section{References}

[1] G.S. Song: Project designing and implemetion: the unified planning and comprehensive integration of college digital campus, (MS. Shandong University, China 2013), P18-20, P27, P31

[2] R.Z. Li: Design and implementation of university network optimization. (MS. Shenyang University of Technology, China 2013.1), P24, P34

[3] Y.Wang: Electronic Technology \& Software Engineering, 2015.1, P23

[4] W.P. Yang: Electronic Technology \& Software Engineering, 2015.2,P42 
[5] Y.L. Li, K.Y. Liu and H.M. Yang: China Audio-Visual Education, 2012.1, P133-P136

[6] G.D. Jing: Software Guide, Vol.12(2013.7) No.7,P13-14 